\title{
Nanoscale Analysis of Manganeous Oxide Rock Varnish on the Smithsonian Castle, Washington, DC
}

\author{
Meredith C. Sharps ${ }^{1 *}$, Edward P. Vicenzi ${ }^{2}$, and Carol A. Grissom ${ }^{2}$ \\ 1. Department of Chemistry and Biochemistry, University of Oregon, Eugene, OR, USA \\ 2. Museum Conservation Institute, Smithsonian Institution, Suitland, MD, USA \\ *Corresponding author: msharps@uoregon.edu
}

The Smithsonian Institution Building, commonly referred to as the "Castle", was completed on the National Mall in Washington, D.C. in 1855 as the first home for the Institution. The Norman-style structure remains the signature building of the Institution, currently housing the visitor center and administrative offices for the museum complex. The Castle is composed of red Seneca sandstone, which has recently been designated a Global Heritage Stone Resource [1]. In 2007, discoloration in the form of dark bluish-black patches were noticed on all façades of the Castle [2]. Portable XRF analysis indicated that these patches contain elevated levels of manganese relative to the bulk sandstone. This analysis is consistent with the formation of "rock varnish," a geological feature most often found on rock surfaces in arid environments and typically composed of clay materials (hydrous aluminum silicates) intimately mixed with $\mathrm{Mn}$ and Fe oxides [3].

Rock varnish is ubiquitous - it forms on all types of rocks in a variety of climates worldwide [4]. However, the presence of varnish on the Castle is one of few documented examples of Mn deposits forming in urban environments. While rock varnish has been studied for over 200 years, the mechanism of Mn transport and enhancement is incompletely understood [5]. Mn, Fe, and clays are likely atmospherically delivered to the rock surface, while Mn enhancement/oxidation could occur by several mechanisms: 1) abiotic enhancement through local physicochemical changes at the stone surface, 2) biological mediation through Mn-oxide producing microbes, or 3) a combination of abiotic and biotic mechanisms. Rock varnish accumulates slowly on the surfaces of stone, between $10-400 \mathrm{~nm} / \mathrm{ka}$, making it difficult to observe the process [6]. The Castle's age $(\sim 170$ years) means that this varnish is young compared to geological varnishes formed over 1-100s ka in geological settings, thus offering the opportunity to investigate incipient varnish formation.

Nanoscale analyses on cross-sections of the Castle varnish prepared by a focused ion beam (FIB) provide a wealth of information that helps constrain varnish genesis. FIB cross-sections were investigated using high resolution (HR) TEM, selected area electron diffraction (SAED), and energy dispersive X-ray spectroscopy (STEM-EDX). These analyses allowed us to determine the crystallinity and mineralogical phase of the manganese oxide, examine the compositional disposition of the varnish layer without contribution from the underlying sandstone, and inform the relative timeline of varnish formation. Four FIB cross-sections were lifted out from surface flakes that were pre-characterized by SEM-based microanalysis for regions exhibiting strong enrichment in Mn, e.g., >100x that of the underlying sandstone. SAED revealed the main crystallographic phase of the varnish to be birnessite, a phyllomanganate (Fig. 1). This birnesitte layer is rich in $\mathrm{Ca}$ and poor in $\mathrm{Si}, \mathrm{Al}$, and Fe, indicating that clays and Fe oxides are not significant components (Fig. 2). Trace minerals are found in the layer at the nanoscale, including barite $\left(\mathrm{BaSO}_{4}\right)$. While $\mathrm{Ba}$ is not observed in the bulk sandstone, it is found in particulate matter located on the sandstone surface and, in some sections, within an aggregate dust layer directly underlying the birnessite. This Ba-bearing environmental dust accrued prior to Mn-oxide formation, informing the relative timing of deposition at the mineral-atmosphere interface. Finally, a thin layer of silica $(\sim 30 \mathrm{~nm})$ overlays the Mn-rich layer in some sections, indicating that a silica glaze is either 
the most recently formed layer or is actively forming on a local scale.

The high mass concentration of Mn oxide in the coating (up to 53\%), as opposed to clays, actually reclassifies this material as a heavy metal skin instead of a varnish [6]. Mn skins and rock varnish have many commonalities, but it is hypothesized that the growth of Mn skins is more likely to be mediated by microbes rather than a purely physicochemical process. We found no evidence of bacterial casts or bacterial mediation. However, the purity of the birnessite phase, the strong enrichment in Mn oxide with few other silicates and clays, and the humid semi-tropical climate in which the film is forming suggest that an abiotic origin is unlikely [7].

\section{References:}

[1] CA Grissom, EM Aloiz, EP Vicenzi and RA Livingston, Geol. Soc. Lond. Spec. Publ. 486 (2018).

[2] EP Vicenzi, CA Grissom, RA Livingston and Z Weldon-Yochim, Herit. Sci. 4 (2016).

[3] RM Potter and GR Rossman, Science 196 (1977), p. 1446.

[4] DS Macholdt et al. Chem. Geol. 459 (2017), p. 91.

[5] RI Dorn and D Krinsley, Geomorphology 130 (2011), p. 91.

[6] RI Dorn in "Rock Coatings", (Elsevier Science, Amsterdam), p. 1.

[7] The authors acknowledge funding from the National Science Foundation through the Graduate Research Internship Program.
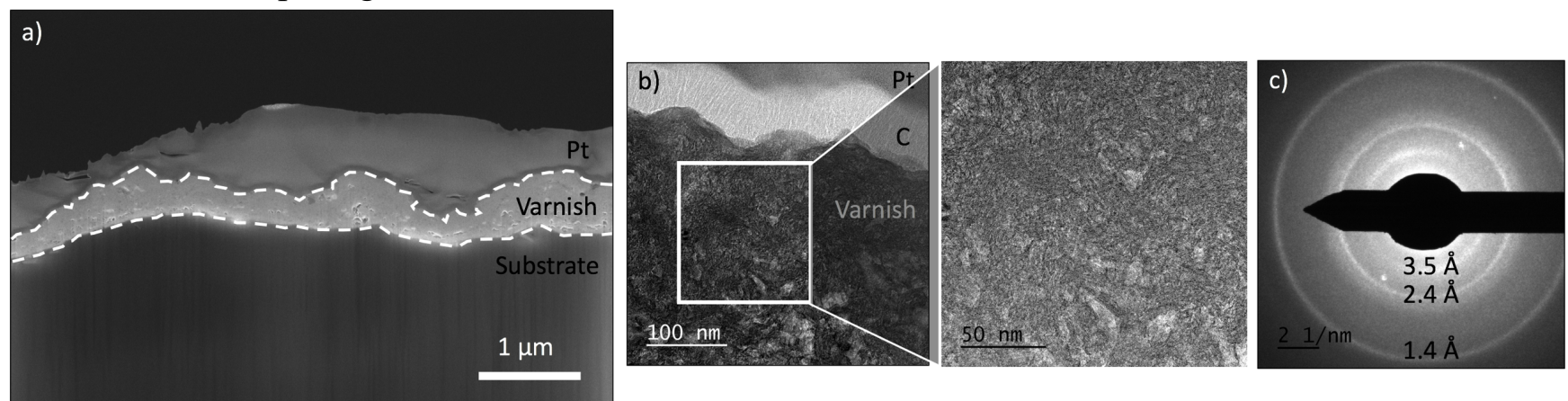

Figure 1. a) Secondary electron image of a FIB cross-section of the varnish layer. b) Bright-field TEM image of the top of the varnish layer. The expanded inset shows the area that was examined for the corresponding diffraction pattern. c) The three rings in the SAED pattern can be indexed to birnessite.
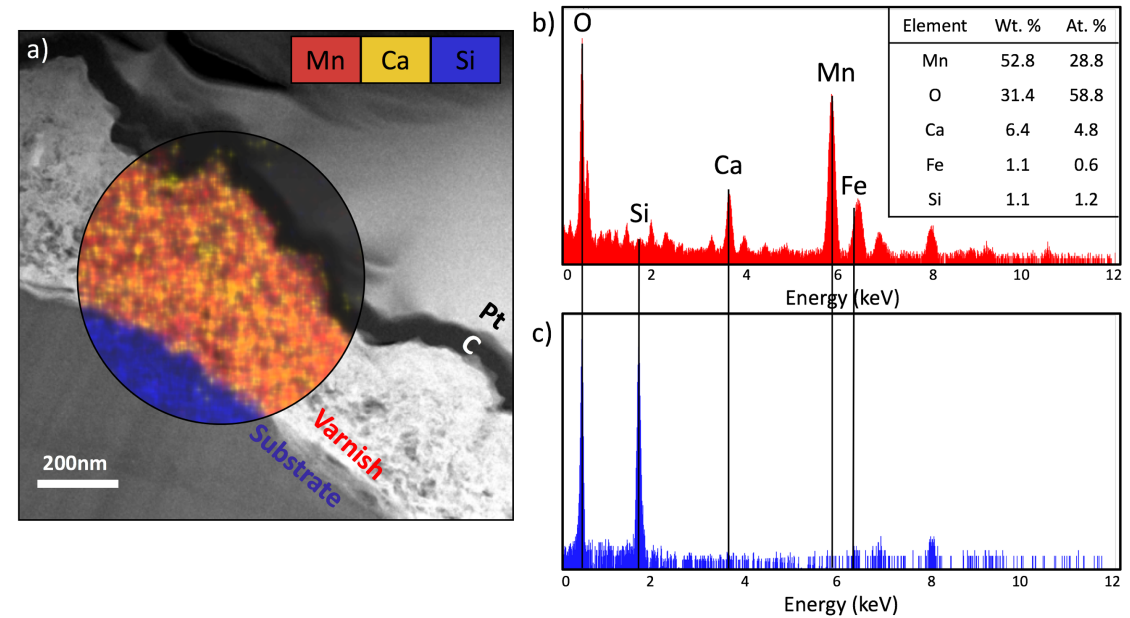

Figure 2. a) High angle annular dark-field (HAADF) STEM image of a FIB lift-out cross section. Encircled area represents a composite X-ray overlay of $\mathrm{Mn}, \mathrm{Ca}$, and $\mathrm{Si}$. Corresponding X-ray spectra integrated across b) the Mn-rich varnish layer (red-filled) and c) the silica substrate (blue-filled). 